\title{
CRÍTICA AO "ESCOLA SEM PARTIDO": UM OLHAR PELA PERSPECTIVA CRÍTICO-SUPERADORA DA EDUCAÇÃO FÍSICA
}

\author{
CRITIQUE OF THE "SCHOOLS WITHOUT PARTIES" MOVEMENT: A LOOK \\ THROUGH THE CRITICAL-OVERCOMING PERSPECTIVE OF PHYSICAL \\ EDUCATION
}

CRÍTICA AL PROGRAMA "ESCUELA SIN PARTIDO": UNA MIRADA DESDE LA

PERSPECTIVA CRIITICO-SUPERADORA DE LA EDUCACIÓN FÍSICA

Guilherme Bardemaker Bernardi*, Carlos Alberto Perdomo Fazenda Junior*

Palavras chave:

Política.

Educação Física.

Ensino.

Filosofia.

\begin{abstract}
Resumo: Este ensaio tem por objetivo analisar e debater criticamente o movimento denominado Escola sem Partido, discutindo sua origem, o contexto sociopolítico no qual ele se desenvolve e quais são as teses que o sustentam. Busca traçar um breve olhar pela área de conhecimento da Educação Física, especificamente pelo viés da perspectiva crítico-superadora, e quais são os desdobramentos e as consequências, imediatas e futuras, para o seu ensino e para o trabalho do professor no âmbito da escola pública. Por fim, sugere possibilidades e ações de enfrentamento ao discurso conservador em defesa de uma educação e uma Educação Física crítica em que alunos e alunas sejam sujeitos ativos do processo de ensino-aprendizagem.
\end{abstract}

Abstract: This essay aims to analyze and critically discuss the movement called "schools without parties", looking into its origin, the socio-political context in which it develops and the arguments that sustain it. It attempts to take a brief look at it through the Physical Education knowledge area, specifically through the critical-overcoming perspective, and see what its immediate and future ramifications and consequences are for PE teaching and PE teachers' work in the public school context. Finally, it suggests possibilities and actions to confront the conservative discourse and advocate critical education and Physical Education in which students are active subjects of the teaching-learning process.

Palabras clave: Política.

Educación Física.

Enseñanza.

Filosofía. que se desarrolla y cuáles son las tesis que lo sostienen. Busca lanzar una breve mirada
Resumen: Este ensayo tiene por objetivo analizar y debatir críticamente el movimiento denominado "Escuela sin Partido", discutiendo su origen, el contexto sociopolítico en el por el área de conocimiento de la Educación Física, específicamente por el sesgo de la perspectiva crítico-superadora, y cuáles son los desdoblamientos y las consecuencias, inmediatas y futuras, para la enseñanza y para el trabajo del profesor en el ámbito de la educación pública. Por último, sugiere posibilidades y acciones de enfrentamiento al discurso conservador en defensa de una educación y de una Educación Física crítica, donde alumnos y alumnas sean sujetos activos del proceso de enseñanza y aprendizaje.
*Universidade Federal do Rio Grande do Sul. Porto Alegre, RS, Brasil. E-mail: bernardi.esef@gmail.com; juniorfazenda@gmail.com

Recebido em: 10-01-2018 Aprovado em: 02-07-2018

DOI: hittps://doi.org/10.22456/1982-8918.79511 (c) (1) (8) Licence 


\section{INTRODUÇÃO}

[...] 'eu já não discuto mais Marx em sala de aula. Eu discuto Adam Smith, mas Marx eu não discuto. Eu não discuto gênero em sala de aula, eu tenho medo de ser processado [...]' (PENNA, 2017, p. 48).

O trecho escolhido para iniciar este texto é o relato de um professor anônimo a Fernando de Araújo Penna, Professor Adjunto da Faculdade de Educação da Universidade Federal Fluminense (UFF), que publicizou esta preocupação na Aula Magna da mesma universidade no ano de 2016, e que foi transcrito e publicado em 2017 enquanto texto. A preocupação deste docente demonstra que 0 até então considerado simples devaneio de um grupo conservador para com a educação brasileira já está em outro patamar.

O Escola sem Partido (ESP) cresce a cada dia, com uma inserção cada vez maior no âmbito legislativo, no senso comum da população brasileira, e, perigosamente, em certa parcela de docentes e pesquisadores em educação. Por isso, a necessidade de compreender sua origem, suas teses e seus argumentos é a melhor forma de propor um debate franco com a sociedade brasileira, buscando desvendar a falácia escondida por trás do "sem partido", para compreender em que medida tal discurso pode interferir e moldar a organização do trabalho pedagógico da Educação Física no âmbito da escola básica, e quais as consequências diretas para o professorado desta área de conhecimento.

Entendemos que o ESP não é o precursor do pensamento conservador na educação brasileira. Historicamente, políticas públicas em educação no Brasil se pautaram hegemonicamente no pensamento conservador, apesar de experiências progressistas que ocorreram e ocorrem no campo da escola, compreendendo-a como um espaço de disputas político-pedagógicas.

Algumas análises partem do livro Escola "sem" partido: esfinge que ameaça a educação e a sociedade brasileira (FRIGOTTO, 2017a), além de autores que debatem criticamente a educação e a sociedade capitalista. No campo específico da Educação Física, a discussão é pautada pela ótica da perspectiva crítico-superadora, viés que tem olhado para a Educação Física na escola a partir de uma visão de mundo antagônica ao que pressupõe o ESP e demais movimentos conservadores contemporâneos.

Ademais, a proposta do ensaio é também tecer críticas contundentes e propositivas ao ESP. Partimos do pressuposto de que, apesar do jogo de palavras convidativo ao senso comum em uma época de criminalização generalizada da política, o "sem partido" tenta esconder sua posição ideológica clara: conservadora e neoliberal.

\section{BERÇO DO ESCOLA SEM PARTIDO: A ASCENSÃO DO NEOCONSERVADORISMO}

Para discutirmos o ESP enquanto fenômeno político e social, faz-se necessário compreender o contexto no qual ele é gerido, cresce e ganha corpo na sociedade brasileira. 0 Projeto de Lei ${ }^{1}$ (PL) que tramita na Câmara Federal (PL 867/2015) que propõe a inclusão, entre as diretrizes e bases da educação nacional, do "Programa Escola sem Partido" é de 2015. A criação do ESP como "movimento" data de 2004, mas sua gênese pode ser considerada não 
apenas este recorte temporal específico, mas, sim, uma conjuntura mais profunda, na qual o modo de produção capitalista enfrenta mais uma de suas grandes crises.

Diferentemente do que ocorreu em outros períodos históricos, Frigotto (2017b) afirma que a crise atual do capitalismo não é cíclica, mas contínua e global. Assim, a forma encontrada para dar conta desse sistema é a centralização de poder cada vez mais em grandes conglomerados econômicos, e cada vez menos com os Estados. Como aponta o autor, um "poder sem sociedade" em um "Estado de exceção permanente". Um poder que se afirma no âmbito cultural, jurídico e cada vez mais em um Estado policial, característico da sociedade neoliberal de nosso tempo. As contradições do atual estágio da sociedade capitalista na sua face mais desigual de todos os tempos, sob a premissa neoliberal é, portanto, uma base sólida e um berço fecundo para reações do tipo ESP. Tais ideias estão embasadas numa visão de mundo que considera a educação como um elemento mercadológico.

O período histórico que vivemos, especialmente considerando o golpe jurídicoparlamentar de 2016 que derrubou a presidenta eleita Dilma Rousseff, abriu precedentes para que a face mais nefasta da ótica neoliberal ganhasse corpo. Os impactos de políticas, como as de contenção de gastos públicos e a série de reformas de Estado, como as já aprovadas Reforma Trabalhista e da Lei das Terceirizações, irão gerar efeitos no âmbito das já difíceis condições de trabalho e salário para a categoria do professorado, como a PEC 55/2016 (BRASIL, 2016b), Proposta de Emenda à Constituição, que limita os gastos públicos pelos próximos 20 anos no país, tendo como base a despesa primária paga de 2016 e com correção apenas da inflação de cada ano.

A visão neoliberal de educação tem sido responsável, principalmente a partir dos anos 1990 no Brasil, por incentivar o mercado educacional, ampliando a participação de grandes conglomerados empresariais no ramo da educação e contribuindo para o desmanche da educação e do papel da escola pública, bem como desvalorizando os trabalhadores e trabalhadoras em educação. Concomitantemente, é neste período que se instaura uma narrativa salvacionista baseada na caridade, onde deve a sociedade civil ajudar na construção e melhorar a educação, e a via escolhida para isso é o voluntarismo, geralmente organizado por Organizações Não Governamentais (ONGs), Institutos e Fundações, quase sempre financiados por grandes empresas.

Essa visão tem tido influência em diversas proposições de políticas públicas e defende uma noção de educação baseada pelos seus interesses, não voltada para a formação do ser humano como um todo, mas baseada em um projeto de sociedade que responsabiliza cada indivíduo por sua condição de vida, e que é dever de cada um investir em si mesmo, criar um "capital humano", para assim competir no mercado e disputar melhores condições de vida.

Segundo Antunes \& Pinto (2007), a teoria do capital humano é uma forma de pensar a educação de um modo utilitarista, que surge em um contexto onde o mundo do trabalho passa a se organizar pela lógica flexível do toyotismo. Foi idealizada pelo economista Theodore Schultz, em meados da década de 1960, e tem por base a ideia de que o trabalhador deve se qualificar dentro das expectativas do mercado, criar um "capital de si mesmo", para então estar preparado para disputar e garantir sua empregabilidade em um contexto no qual deve estar cada vez mais disponível a "aprender a aprender". 
Para Frigotto (2017b), a construção ideológica da noção de capital humano induz a uma visão invertida da desigualdade, estabelecendo uma mudança profunda e regressiva na concepção republicana de educação básica, pública, gratuita, universal e laica. A educação escolar passa a ser regida pelos critérios e leis mercantis, e, portanto, deixa de ser concebida como um direito social e universal. Para tal visão ter sucesso, é necessário instituir uma lógica que defina um conhecimento "certo", útil ao atual modo de organização da vida. É nesse contexto que se insere o Escola sem Partido e sua visão notoriamente mercantil, mas, acima de tudo, ultraconservadora.

Da premissa que o(a) estudante é um "cliente", então o que deve ser oferecido como mercadoria deve satisfazer somente a quem compra. Por isso, não é de se estranhar que 0 criador do PL Escola sem Partido, o procurador Miguel Nagib, tenha afirmado em audiência pública da Comissão de Educação do Senado Federal, em $1^{\circ}$ de setembro de 2016, que uma das referências para criar o citado projeto de lei tenha sido o Código de Defesa do Consumidor ${ }^{2}$. Nessa lógica, o "cliente" tem sempre razão, e, dessa forma, aqueles que hoje fazem a mediação da "entrega", os professores, não podem interferir na escolha do comprador, devendo receber o conhecimento "neutro":

O Escola sem Partido expressa o epílogo de um processo que quer estatuir uma lei que define o que é ciência e conhecimentos válidos, e que os professores só podem seguir a cartilha das conclusões e interpretações da ciência oficial, uma ciência supostamente não neutra. Para isso, manipula até mesmo o sentido liberal de política, induzindo a ideia de que a escola no Brasil estaria comandada por um partido político e seus profissionais e os alunos seres idiotas manipulados (FRIGOTTO, 2017b, p.29).

O período pós-golpe de 2016 tem sido fecundo e dado abertura para que setores conservadores da sociedade ganhem corpo, disputem o senso comum e "saiam do armário", de forma a disputar espaços na sociedade e na política, como é o caso do Movimento Brasil Livre (MBL) e o Escola sem Partido.

O MBL, por exemplo, defende, de acordo com as propostas aprovadas no seu primeiro congresso ${ }^{3}$, em 2015: a implementação de vouchers na educação em todos os níveis; legalização do homeschooling; gestão privada de escolas públicas; militarização de escolas em áreas de risco; e a defesa da apresentação do projeto Escola sem Partido em legislativos estaduais e municipais. É intrínseca a esses grupos uma visão societária que vê em tudo a possibilidade de mercadorização, um retorno a um fundamentalismo mercantil, no qual o Estado apenas atrapalha o livre comércio. Para além da lógica mercantil, projetos como esse têm como base não só ideias econômicas neoliberais, mas posturas conservadoras no âmbito cultural.

É possível identificar, tanto no MBL quanto no Escola sem Partido, elementos claros do que Apple (2003) denominou de Modernização Conservadora, como sendo uma aliança que reivindica o mercado competitivo como solução para tudo e que defende um "resgate" do que chamam "cultura tradicional", uma reverência a Deus, e métodos de controle cada vez maiores para 0 âmbito educacional.

Para isso, conta com o aporte teórico e ideológico do neoliberalismo para consolidar sua visão de educação, mas que não seria passível de ser colocada em prática se não fosse 
um dos braços fundamentais da aliança direitista, que é o grupo denominado por Apple (2003) de "Neoconservadores". Estes baseiam-se na ideia de defender os seus "princípios morais", e lutam por um retorno a um tempo no qual a escola ensinava um "verdadeiro saber", quando a moralidade reinava. Propõem currículos obrigatórios em vários níveis, provas padronizadas e o retorno ao "padrão de qualidade", defendem o patriotismo e suas variantes conservadoras.

[...] os neoconservadores lamentam o 'declínio' do currículo tradicional e da história, da literatura e de valores que dizem que ele representava. Por trás dessa preocupação está uma série de pressupostos históricos sobre 'tradição', sobre a existência de um consenso social em relação ao que deve ser considerado um saber legítimo e sobre superioridade cultural [...] (APPLE, 2003, p. 59).

Além do controle sobre o saber legítimo, os neoconservadores querem um Estado forte na regulamentação no que diz respeito aos professores. Apple chama a atenção para a guinada da "autonomia permitida" para a "autonomia regulamentada", na qual o trabalho dos professores é padronizado, racionalizado e policiado. A análise de Apple, apesar de ter sido feita em um contexto de mais de uma década atrás nos Estados Unidos, parece ter sido escrita para a realidade atual brasileira. Segundo seu sítio eletrônico, o programa Escola sem Partido

[...] foi criado para dar visibilidade a um problema gravíssimo que atinge a imensa maioria das escolas e universidades brasileiras: a instrumentalização do ensino para fins políticos, ideológicos e partidários. E o modo de fazê-lo é divulgar o testemunho das vítimas, ou seja, dos próprios alunos [...] (ESCOLA SEM PARTIDO, 2017).

O discurso do "sem partido" se utiliza de um desgaste histórico do povo brasileiro com a classe política e em geral, com os partidos políticos. É um jogo semântico que cativa e captura as pessoas mais desavisadas, pois, se os partidos, ou mais especificamente um partido estaria fazendo tão mal ao país, uma escola com/a serviço de um partido é ruim para o país e uma escola sem partido é boa para o país. Não à toa, o movimento/organização se

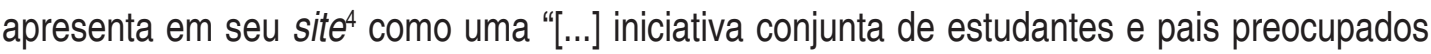
com o grau de contaminação político-ideológica das escolas brasileiras, em todos os níveis: do ensino básico ao superior". Ainda, afirma lutar pela "descontaminação e desmonopolização política e ideológica das escolas", pois, segundo o site, existe um "exército organizado de militantes travestidos de professores" que querem impor aos estudantes sua visão de mundo, que, segundo a organização do movimento, são visões "esquerdistas", incluindo a "ideologia de gênero", bem como a defesa do marxismo e suas vertentes, e que seriam defendidas, principalmente, pelo Partido dos Trabalhadores (PT).

\section{A NEGAÇÃO DO TRABALHO DOCENTE E A OBJETIFICAÇÃO DO EDUCANDO}

No período histórico atual, o Escola sem Partido surge como "fiscalizador" de uma educação moral e de retorno à "boa educação". Mas o que aparece agora nada mais é do que uma tentativa conservadora que busca resgatar um passado glorioso que não encontra correspondência com a realidade. A ideia de uma "era de ouro", onde tudo, num passado romantizado era "bom" e "funcionava", já mostrou sua cara em outras épocas, e tende a aparecer, com a ajuda de setores conservadores e das classes dominantes, em momentos históricos nos quais há o avanço de direitos sociais para setores da sociedade historicamente excluídos.

4 Disponível em: <http://escolasempartido.org/quem-somos> $>$. Acesso em: 1ํo nov. 2017. 
Tomemos, a título de exemplo, a chamada "Marcha da Família com Deus pela Liberdade", um conjunto de atos massivos contra o então presidente João Goulart, ocorrido poucos dias antes do golpe civil-militar de 1964, pela suposta "ameaça comunista" que representava o governo de então.

Não à toa, o termo "liberdade" aparecia como sendo o objetivo da marcha. A liberdade ali defendida já aparentava um sentido capitalista, de cunho mercadológico, se levarmos em consideração que as reformas defendidas por Jango incluíam estatização de refinarias, desapropriação de terras, dentre outras reformas de base, que incomodaram os grandes conglomerados empresariais e a grande mídia.

Apple (2003), ao analisar o movimento da direita e o avanço da modernização conservadora na educação, aponta que o conceito de "liberdade" é cada vez mais contestado por estes grupos. O autor retoma o liberalismo clássico do século XVIII, no qual a noção estava atrelada à independência ao governo, ou seja, era livre quem tivesse independência tanto da vida privada, quanto economicamente em relação ao Estado. Do ponto de vista do avanço das lutas pela liberdade pessoal, 0 autor salienta o envolvimento dos movimentos sociais que radicalizam e se organizam, a fim de reivindicar uma liberdade plena para os grupos historicamente excluídos, mas que se tornam liberdades coletivas, a serem incrementadas pelo Estado como Políticas Públicas.

Porém, para Apple, as liberdades coletivas estão cada vez mais ameaçadas na medida em que a direita consegue girar o senso comum para a ideia de liberdade como sinônimo de mercado. E, para isso, a necessidade de que o mercado desregulamentado seja a expressão máxima da liberdade individual. É possível considerar que o Escola sem Partido, tal qual já ocorrera em outras épocas no país, busque tensionar o conceito de liberdade, ao passo que tenta restringir as liberdades dos educandos e dos docentes quando defende a ideia de "professor não é educador". Essa tese nada mais é do que a objetificação do educando e a negação total do trabalho docente.

Penna (2017) vai sustentar a ideia de que o fenômeno educacional do ESP se sustenta em quatro pilares:

1) concepção de escolarização: porque o movimento defende que o professor não é educador, que o dever do professor é apenas instruir e que a educação é responsabilidade da família.

2) desqualificação do professor: desqualifica o professor como um profissional ético e responsável por aquilo que faz. A desqualificação do professor passa também por uma ideia de educação calcada no mercado, numa relação consumidor $x$ serviço prestado. Além disso, o PL No 867/2015 (BRASIL, 2015) exclui as competências ligadas ao professor e retira dele a liberdade de expressão no exercício de seu trabalho.

3) estratégias discursivas fascistas: o autor enfatiza que não é possível dizer que o ESP seja de fato fascista, mas que sim, utiliza estratégias discursivas fascistas. Quais são estas estratégias: desumanização do professor, preocupação com o grau de "contaminação político-ideológica", utilização de termos e expressões de impacto que desqualificam como "exército organizado de militantes travestidos de professores". Boa parte destas estratégias discursivas são veiculadas em redes sociais em forma de memes ofensivos à imagem do professorado 5 .

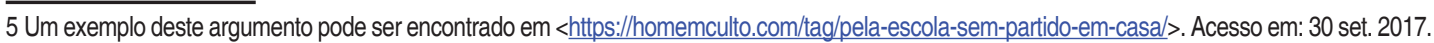


4) defesa do poder total dos pais sobre os filhos: a partir da ideia de que o Estado "usurpou" o direito dos pais sobre a educação moral dos filhos, o PL aponta o direito aos pais que seus filhos recebam a educação moral que esteja de acordo com suas próprias convicções. Entretanto, como indaga Penna (2017), como garantir a proibição da veiculação de algo que contradiga os valores de uma turma toda completamente heterogênea? Por isso 0 autor defende a necessidade da formação para cidadania e formar para a cidadania pressupõe reconhecer entre nós a diferença.

Ainda sobre o contexto do fenômeno ESP, Algebaile (2017) vai apontar que parte das estratégias utilizadas incluem táticas difamatórias, tons jocosos e desrespeitosos, suposto embasamento científico, tom de denuncismo. E acrescenta que não é possível defini-lo como movimento propriamente dito, principalmente pelo caráter personalista adotado, apesar de parecer composto de forma horizontal e plural, é bastante coordenado e tem uma centralidade política bem-definida, com os setores conservadores da sociedade.

O ESP está calcado na ideia de que um determinado conhecimento possa ser desprovido de parcialidade, como se a própria ciência fosse neutra. A farsa remonta à tragédia com uma educação pura e simples de transmissão de conhecimento, uma guinada total à concepção bancária de educação, na qual os educandos são tratados como tábulas rasas, na qual o papel do professorado é apenas despejar o conhecimento em cima, eliminando fatores importantes deste processo: a intrínseca e dialética relação educador/educando.

Por que não estabelecer uma 'necessária intimidade' entre os saberes curriculares fundamentais aos alunos e a experiência social que eles têm como indivíduos? Por que não discutir as implicações políticas e ideológicas de um tal descaso dos dominantes pelas áreas pobres da cidade? A ética de classe embutida neste descaso? Porque, dirá um educador reacionariamente pragmático, a escola não tem nada a ver com isso. A escola não é partido. Ela tem que ensinar os conteúdos, transferi-los aos alunos. Aprendidos, estes operam por si mesmos (FREIRE, 2008, p.34).

Além disso, Paulo Freire (2008, p. 141) nos recorda que "ensinar exige reconhecer que a educação é ideológica". E a sua crítica é em relação a toda educação ideológica capitalista que trata a atual condição da humanidade não como uma construção da própria humanidade, mas como algo natural, algo superior, que nos condicionou a isto, e que só nos resta aceitar. Essa forma de ver o mundo é responsável por mantermos, ainda no século XXI, determinados pensamentos que camuflam a realidade, mas que ganham status de senso comum, como aceitar docilmente o discurso fatalista neoliberal, e que o que é válido hoje é o "pragmatismo" pedagógico, é o treino técnico-científico do educando (FREIRE, 2008).

Desta forma, o diálogo com o campo específico da Educação Física vai ao encontro de um debate importante ao longo dos últimos anos: qual o papel da Educação Física na escola? Considerando os múltiplos olhares que o campo recebe para o seu processo de ensino/ aprendizagem, a indagação que nos cabe neste breve texto é refletir sobre os impactos do ESP na Educação Física na escola, principalmente para o viés que tem se proposto a discutir criticamente e refletir sobre a cultura corporal no ambiente escolar. 


\section{A EDUCAÇÃO FÍSICA: REFLEXÃO SOBRE A CULTURA CORPORAL OU REPRODUÇÃO? CONSEQUÊNCIAS DO ESCOLA SEM PARTIDO NA EDUCAÇÃO FíSICA ESCOLAR}

A compreensão dos efeitos do projeto Escola sem Partido na Educação Física nos propõe um exercício de reflexão acerca das teorias que fundamentam a área escolar, mais especificamente sobre aquelas que resultam do movimento renovador do início dos anos 1980.

De acordo com Bracht et al. (2011), a produção acerca da Educação Física Escolar nos principais periódicos da área durante a década de 1980 era orientada predominantemente pelo pensamento marxista, no qual as principais problematizações giravam em torno da crítica ao esporte alienante, o lugar da Educação Física na escola e o seu papel social, bem como a função da Educação Física no mundo do trabalho capitalista.

Esse acúmulo de debates proporcionou reflexões sobre a prática da Educação Física na escola, resultando em produções que ainda hoje repercutem no campo do ensino e fundamentam teórica e metodologicamente a prática de muitos docentes. Dentre as diversas proposições teórico-metodológicas oriundas deste período, escolhemos para o debate neste ensaio a concepção crítico-superadora, formulada por um Coletivo de Autores em sua obra Metodologia do Ensino da Educação Física (SOARES et al. 1992). Esta escolha é intencional, partindo do entendimento que essa perspectiva teórica e metodológica se baseia em premissas de contraposição à lógica societária capitalista, tendo por base as ideias do materialismo histórico dialético, exatamente a concepção de mundo mais atacada pelos defensores do ESP.

A compreensão de projeto político-pedagógico da concepção crítico-superadora expressa uma intervenção em determinada direção, já que reflete sobre a ação da humanidade na realidade (SOARES et al. 1992). Neste sentido, o Coletivo de Autores argumenta ainda que a pedagogia crítico-superadora busca atender às demandas da classe trabalhadora, visto que possui uma perspectiva de classe e se posiciona enquanto modificadora da realidade buscando a transformação social.

Essa concepção busca valorizar não somente o conteúdo, mas também uma contextualização de como este foi construído e modificado ao longo do tempo, revelando preocupação com a compreensão da historicidade dos conteúdos. Ou seja, não somente sobre o que ensinar, mas também sobre como esses conhecimentos foram construídos, valorizando a contextualização dos fatos e o resgate histórico para que também se compreenda 0 caráter provisório do conhecimento. A abordagem crítico-superadora tem por objetivo possibilitar ao estudante a compreensão do seu papel enquanto sujeito histórico, social e produtor de conhecimento ao contextualizar historicamente os temas selecionados de acordo com a relevância social.

O objeto de estudo da Educação Física, segundo a concepção crítico-superadora, é a cultura corporal, que engloba elementos como jogos, esportes, ginásticas, lutas e danças, e todas as formas de atividades particularmente corporais constituídas por significações subjetivas produzidas pela consciência social e "que podem ser identificados como formas de representação simbólica de realidades vividas pelo homem, historicamente criadas e culturalmente desenvolvidas" (SOARES et al. 1992, p. 26). 
Essa concepção, surgida com a reabertura democrática da sociedade, no período pósditadura e com o movimento renovador da Educação Física, tende a sentir os impactos de um projeto neoconservador como o ESP. Ainda mais por se tratar de uma concepção que se contrapõe às práticas que contribuem para a manutenção da sociedade capitalista, e que tem como objeto a reflexão sobre a cultura corporal a partir da emancipação por meio da liberdade de expressão dos movimentos, negando a exploração do ser humano pelo ser humano, reafirmando os interesses da classe trabalhadora.

Ainda que este debate já tenha sido feito por outros autores, ressaltamos que elementos biológicos e técnicos constituem o objeto de estudo da Educação Física, em conjunto com os demais elementos da cultura corporal e, portanto, não devem ser negados no ambiente escolar. A crítica já realizada anteriormente diz respeito à exclusividade do ensino destes aspectos, desconsiderando a historicidade, relevância social, e a reflexão acerca desses e de demais temas.

Ao se pautar pelo discurso da justiça social e tendo o materialismo histórico dialético enquanto método de análise da realidade, a concepção crítico-superadora, inspirada nas obras de autores da área da Educação, como Dermeval Saviani e José Carlos Libâneo, torna-se um possível alvo dos mecanismos de monitoramento do Escola sem Partido. Dentre as situações mais detalhadas sobre as quais se debruça o ESP, às quais seus princípios gerais se aplicariam de fato, podemos identificar a preocupação com temáticas que problematizam as concepções políticas, socioculturais e econômicas hegemônicas (FRIGOTTO, 2017b, p. 67), dentre elas, perspectivas que teçam críticas ao capitalismo e à educação conservadora.

Não à toa, um dos grandes "alvos" do ESP e do neoconservadorismo tem sido o que eles denominam "ideologia de gênero", uma expressão utilizada como jargão em tom pejorativo, para tentar eliminar do debate educacional toda e qualquer discussão acerca dos grandes problemas que vivemos no país acerca do preconceito e dos níveis alarmantes de violência contra a população LGBT, bem como a violência contra mulheres. Mattos et al. (2017, p.94) afirmam que:

Como vem sendo pautado pelos partidários do Escola sem Partido, o combate à 'ideologia de gênero' apaga as demandas das educadoras e dos educadores que conhecem o cotidiano das escolas, suas necessidades e seus problemas, e que se veem diariamente desafiados por questões de gênero e sexualidade que eclodem em suas salas de aula, corredores e pátios.

Em um contexto em que temas transversais não possam ser livremente tratados, por serem considerados "ideologizantes", como sugere o projeto Escola sem Partido, de que forma estudar danças na Educação Física na escola sem debater gêneros e papéis sociais historicamente construídos? Ou, como compreender o porquê de alguns esportes ainda serem considerados "coisa de homem" e outros "coisa de mulher"?

Abordando pelo viés da compreensão mais ampla da sociedade, como seria conhecer sobre esportes sem considerar os impactos sociais dos megaeventos esportivos, tais como Olimpíadas e Copa do Mundo? Estaríamos limitados ao que acontece "dentro das quatro linhas"?

Como trabalhar em sala de aula com a capoeira, por exemplo, sem discutir sobre a escravidão de homens e mulheres, negros e negras, por homens brancos e a desigualdade racial que ainda existe em nosso país, e que atinge também uma grande parcela dos alunos e alunas das redes públicas de ensino? 
Seria possível tratar sobre a evolução dos métodos ginásticos sem refletir sobre a sociedade do consumo e o boom dos sistemas e métodos patenteados? E como conhecer sobre os jogos sem sequer considerar as culturas indígenas e africanas? De que forma seria possível uma Educação Física Escolar "sem partido"?

Em tal conjuntura, haveria um movimento de esvaziamento do objeto de estudo da Educação Física, bem como do seu papel social enquanto conhecimento historicamente construído. O conhecimento a ser valorizado passaria a ser exclusivamente de cunho utilitarista, desde que esta utilidade esteja voltada para a lógica capitalista e seus valores. Logo, conhecimentos relativos a atividade física e saúde reforçariam a lógica da responsabilização do indivíduo, na medida em que este, aportado teoricamente sobre as benesses do movimento, inevitavelmente passaria a adotar um estilo de vida "saudável", desconsiderando as condições sociais e culturais que permeiam a existência deste sujeito, bem como a impossibilidade de uma reflexão e contestação de noções hegemônicas de atividade física, lazer, esporte e saúde.

Concomitantemente, haveria um esvaziamento da função docente, representando uma hegemonia conteudista sobre os demais aspectos que compõem a organização do trabalho pedagógico, compondo um cenário em que o professor se tornaria um mero instrutor, pois teríamos instaurada a "mordaça", o que impossibilitaria os professores e professoras de ampliar reflexões sobre os conhecimentos construídos na relação educador/educando, bem como criaria um clima policialesco em sala de aula, na medida em que tratar determinados assuntos seria considerado um crime e/ou contravenção.

Ao considerarmos uma Educação Física no contexto do projeto ESP, somos remetidos à ampliação de uma prática alienadora, com poucas possibilidades de superação do atual modo de organização da sociedade, reforçando uma lógica hegemônica já estabelecida historicamente pelas políticas públicas de Educação, as quais são mais conservadoras do que progressistas. Neste cenário, a Educação Física inserida no contexto escolar resultaria na criminalização de uma perspectiva crítico-superadora e de reflexões sobre o objeto de estudo e seu caráter integral.

\section{CONSIDERAÇÕES FINAIS}

As reflexões deste breve texto tiveram como objetivo suscitar o debate acerca do ESP como fenômeno educacional, e pinçar o debate especificamente no âmbito da Educação Física. Compreendemos, entretanto, que este debate é amplo e interessa ao conjunto de educadores e educadoras de todo o país que estejam comprometidos com uma educação pública, gratuita e de qualidade. O ESP não pode mais ser tratado como caso isolado, deve ser compreendido, debatido e, principalmente, rebatido.

Como reforça Algebaile (2017), a estratégia que tem sido utilizada para propagandear os ideais da "família" e lutar contra a "doutrinação" não necessita necessariamente de um PL aprovado. A simples existência do PL cumpre esse papel de estímulo à vigilância. Já temos $\operatorname{casos}^{6}$ no país de afronta à liberdade de professores e professoras no exercício da sua função, e isso deve ser encarado como mais um avanço do processo neoconservador que quer se instaurar no país. 
É importante lembrarmos, contudo, que há resistência ao ESP, principalmente articulada a partir da criação da "Frente Nacional Escola Sem Mordaça". Esta Frente ${ }^{7}$ foi deliberada no II Encontro Nacional de Educação (II ENE), realizado em Brasília/DF, em 2016, e luta contra a aprovação dos projetos de lei relativos ao ESP em todas as esferas legislativas.

Ainda, há no âmbito legislativo o apoio de parlamentares que defendem a liberdade de expressão e da pluralidade de ideias no âmbito da educação básica, inclusive protocolando Projetos de Lei em contraponto ao ESP, como o PL № 6005 de 2016, de autoria do Deputado Jean Wyllys (Partido Socialismo e Liberdade), que defende a "Escola Livre", a partir da defesa de uma escola com muitas ideias e com muita análise crítica sobre o mundo, na qual a escola democrática é aquela que pratica a democracia em seu cotidiano (BRASIL, 2016a).

Por isso, reafirmamos aqui nossa posição, que vai ao encontro do conjunto de educadores e educadoras que defendem o direito à liberdade de expressão e de ideias no livre exercício do pensamento do professorado e estudantes, no encontro mediado pelo conhecimento produzido e acumulado histórica e socialmente.

No âmbito da Educação Física, o debate deve ser inserido não só na área de conhecimento específica, mas a compreendendo como integrante do currículo escolar, enfatizando seu aspecto histórico e social e o papel que deve e pode cumprir na escola. Compreendemos que a construção do conhecimento nas aulas se dá através de uma relação indissociável entre educador/educando, e a cultura corporal não pode ser trabalhada e nem feita a sua reflexão num viés em que a única voz seja a do professor ou da professora. Isto, entretanto, não significa que o(a) docente, na condição de autoridade, se exima da sua função social de instigar o debate e, principalmente, como sempre nos sugere a máxima freiriana, ser o problematizador da realidade.

Por isso, é preciso defender que não haja uma Escola sem Partido, nem uma "Educação Física sem partido", pois, se houver, ela será limitada e atenderá especificamente ao grupo historicamente já favorecido na sociedade brasileira. A Educação Física e a educação como um todo devem promover os(as) estudantes como seres pensantes e ativos de sua própria realidade. Eles e elas não são simples depositários de conteúdos e, portanto, não podem ser tratados como se fossem facilmente "manipulados" pelo que faz um(a) docente.

\section{REFERÊNCIAS}

ALGEBAILE, Eveline. Escola sem Partido: o que é, como age, para que serve. In: FRIGOTTO, Gaudêncio (Org.). Escola "sem" partido: esfinge que ameaça a educação e a sociedade brasileira. Rio de Janeiro: UERJ, LPP, 2017. p. 63-74.

ANTUNES, Ricardo; PINTO, Geraldo. A fábrica da educação: da especialização taylorista à flexibilização toyotista. São Paulo: Cortez, 2017.

APPLE, Michael. Educando à direita: mercados, padrões, Deus e desigualdade. São Paulo: Cortez/Instituto Paulo Freire, 2003. (Biblioteca Freiriana, 5). 
BRACHT, Valter et al. A Educação Física Escolar como tema da produção do conhecimento nos periódicos da área no Brasil (1980-2010) Parte II. Movimento, v. 18, n. 2, p.11-37, abr.jjun. 2012.

BRASIL. Projeto de Lei N. 867 de 2015. Inclui, entre as diretrizes e bases da educação nacional, o "Programa Escola sem Partido". Disponível em: <http://www2.camara.leg.br/atividade-legislativa/ comissoes/comissoes-permanentes/ce/audiencias-publicas-1/apresentacoes/apresentacao-miguelnagib>. Acesso em: 30 nov. 2017.

BRASIL. Projeto de Lei N. $\mathbf{6 0 0 5}$ de 2016a. Institui o programa "Escola livre" em todo o território nacional. Disponível em: < http://www.camara.gov.br/proposicoesWeb/prop mostrarintegra?codteor=1484506 >. Acesso em: 30 nov. 2017.

BRASIL. Proposta de Emenda à Constituição n 55, de 2016b: Altera o Ato das Disposições Constitucionais Transitórias, para instituir o Novo Regime Fiscal, e dá outras providências. Disponível em: < http://www.camara.gov.br/proposicoesWeb/prop mostrarintegra?codteor=1468431>. Acesso em: 30 nov. 2017.

ESCOLA SEM PARTIDO. Disponível em: <http://escolasempartido.org/quem-somos> Acesso em: 30 nov. 2017.

FREIRE, Paulo. Pedagogia da autonomia: saberes necessários à prática educativa. 37. ed. São Paulo: Paz e Terra, 2008.

FRIGOTTO, Gaudêncio (Org.) Escola "sem" partido: esfinge que ameaça a educação e a sociedade brasileira. Rio de Janeiro: UERJ, LPP, 2017a.

FRIGOTTO, Gaudêncio. A gênese das teses do Escola sem Partido: esfinge e ovo da serpente que ameaça a sociedade e a educação. In: FRIGOTTO, Gaudêncio (Org.) Escola "sem" partido: esfinge que ameaça a educação e a sociedade brasileira. Rio de Janeiro: UERJ, LPP, 2017b. p. 17-35.

MATTOS, Amana et al. Educação e liberdade: apontamentos para um bom combate ao Projeto de Lei Escola sem Partido. In: FRIGOTTO, Gaudêncio (org.) Escola "sem" partido: esfinge que ameaça a educação e a sociedade brasileira. Rio de Janeiro: UERJ, LPP, 2017. p. 87-104.

MOVIMENTO BRASIL LIVRE. Propostas aprovadas no primeiro congresso do Movimento Brasil Livre em Novembro de 2015. Disponível em: <http://mbl.org.br/wordpress/wp-content/ uploads/2017/05/propostas-mbl.pdf> . Acesso em: 30 nov. 2017.

PENNA, Fernando. O Escola sem Partido como chave de leitura do fenômeno educacional. In: FRIGOTTO, Gaudêncio (Org.) Escola sem" partido: esfinge que ameaça a educação e a sociedade brasileira. Rio de Janeiro : UERJ, LPP, 2017. p. 35-48.

SOARES, Carmen et al. Metodologia do ensino da Educação Física. São Paulo: Cortez, 1992.

URGENTE: PM prende professores em panfletagem contra o Escola Sem Partido em Santo André. ESQUERDA ONLINE, 20 set. 2017. Disponível em: < http://www.esquerdadiario.com.br/URGENTEPM-prende-professor-em-panfletagem-contra-o-Escola-Sem-Partido-em-Santo-Andre>. Acesso em: 30 set. 2017.

VEREADOR gera polêmica ao pedir plano de aula de professora municipal. Diário da Fronteira, Uruguaiana, 24 ago. 2017. Disponível em: <https://diariodafronteira.blogspot.com.br/2017/08/ vereador-gera-polemica-ao-pedir-plano.html>. Acesso em: 30 set. 2017. 